\title{
FUERZAS MILITARES EN CENTROAMÉRICA: A 30 AÑOS DE LA FIRMA DE LOS ACUERDOS DE PAZ
}

\author{
MILITARY FORCES IN CENTRAL AMERICA: TO 30 YEARS OF \\ SIGNATURE OF PEACE AGREEMENTS.
}

Hazel Villalobos Fonseca ${ }^{1}$

ORCID: 0000-0002-2120-8690

\section{RESUMEN}

En las décadas de los setenta y ochenta del siglo XX, las fuerzas militares fueron actores claves en los regímenes autoritarios de Centroamérica. La tutela militar que ofrecieron a estos gobiernos provocó los conflictos armados y desestabilización de las democracias centroamericanas. Por lo cual, los Acuerdos de Paz de la década de los noventa señalaron como principal factor de pacificación y democratización, en la región, la subordinación del poder militar al poder civil en Centroamérica. Hoy, a tres décadas de este proceso, las fuerzas militares de Guatemala, El Salvador, Honduras y Nicaragua se han fortalecido y han adoptado funciones de seguridad ciudadana ante la insuficiencia de las débiles policías nacionales civiles para luchar contra las dinámicas del crimen organizado que afecta a esta región. Este artículo evidencia el fortalecimiento de estas fuerzas militares en estos Estados de derecho aún en consolidación e indica una señal de alerta ante la posibilidad de que la historia de las décadas de los setenta y ochenta se repita en Centroamérica.

Palabras clave: Remilitarización; fuerzas militares; Centroamérica; paz; Estados de derecho; Acuerdos de Paz de Centroamérica.

\begin{abstract}
In the seventies and eighties of the twentieth century military forces were key actors in the authoritarian regimes of Central America. The military tutelage offered to these governments provoked armed conflicts and destabilization of the Central American democracies. The Peace Agreements of the 1990s pointed to the subordination of military power to civil power in Central America as the main factor of pacification and democratization in the region. Three decades later, the military forces of Guatemala, El Salvador, Honduras and Nicaragua have been strengthened and have adopted citizen security functions in the face of the insufficiency of the weak national civil police to fight against the dynamics of organized crime that affect this region. This article demonstrates the strengthening of these military forces in these states of law still that are still in consolidation and indicates a warning signal to the possibility that the history of the seventies and eighties is repeated once again Central America.
\end{abstract}

Keywords: remilitarization; armed forces; Central America; peace; rule of law; Peace Agreements of Central America.

1 Bachiller en Relaciones Internacionales, Universidad Nacional. Especialista en Seguridad y Policía. Costa Rica, San José. haz_jimena@hotmail.com. 


\section{Introducción}

La región centroamericana durante las últimas tres décadas ha experimentado un proceso de democratización en procura de dejar atrás años de inestabilidad política, regímenes autoritarios, violencia y enfrentamientos armados; incluidas sangrientas guerras civiles que cobraron miles de vidas.

Los incipientes Estados de derecho que se construyen en Centroamérica (con excepción de Costa Rica) han sido forjados a partir de la década de los ochentas, en el marco de los Acuerdos de Paz (Esquipulas I y II). En estos Acuerdos de Paz se inauguró un proceso de pacificación de la región, basado en el desarme de los grupos combatientes, la desmilitarización de los países y el paso a elecciones democráticas.

En 1995, casi una década después de estos Acuerdos de Paz de Esquipulas, los presidentes centroamericanos suscribieron otro instrumento para profundizar la paz y garantizar la estabilidad y la seguridad de la región: el Tratado de Marco de Seguridad Democrática (TMSD). Lamentablemente, con el TMSD concluye una época de oro en el proceso de pacificación y democratización de Centroamérica. El ímpetu modernizante y democratizador pareció durar apenas una década, ya que es precisamente hacia finales del siglo anterior que la región empieza a enfrentar crecientes niveles de inseguridad que, de manera paulatina, la han alejado del espíritu de los Acuerdos de Esquipulas y del TMSD.

El fantasma autoritario renació y los ejércitos, que se asumían habían regresado a sus cuarteles al finalizar las guerras internas, volvieron a las calles ahora para enfrentar las nuevas amenazas a la seguridad nacional, ya no desde la doctrina de la seguridad nacional, sino ante la incapacidad estatal de enfrentar la inseguridad y la violencia. Todo con el enfoque de securitización de la seguridad ciudadana (Dammert y Díaz, 2006).

Las fuerzas militares han pasado de ser un actor tradicional en la política de defensa, a un actor importante en la política de seguridad ciudadana de los países centroamericanos. Este es el problema que se analiza en esta investigación, referente a la remilitarización centroamericana en el marco de la crisis de inseguridad y violencia que enfrenta esta región, que revierte lo acordado en los Acuerdos de Paz de Esquipulas y el TMSD.

A tres décadas de los Acuerdos de Paz, es necesario evidenciar, si el proceso de desmilitarización y la subordinación del poder militar al poder civil ha sido real o aún es parte de una utopía que solo se refleja en los discursos presidenciales. 
Por lo cual, el problema de investigación de este artículo es ¿A 30 años de la firma de los Acuerdos de Paz de Centroamérica, los países de Guatemala, Honduras, Nicaragua y El Salvador han avanzado en el proceso de desmilitarización y subordinación del poder militar al poder civil, plasmados en estos tratados para lograr la pacificación y democratización de esta región del mundo?

Este trabajo es de particular relevancia para quienes estudian el tema de seguridad en la región, los entes decisores, los grupos y líderes políticos regionales, la disciplina de las Relaciones Internacionales, así como para cualquier otra persona interesada en el tema, en cuanto contribuye al conocimiento de los procesos de desmilitarización de los países centroamericanos en el marco de dinámicas de pacificación y democratización, como un factor clave para alcanzar la democracia, y la paz plena y duradera en la región centroamericana.

Esta investigación pretende evidenciar si se logró el propósito de desmilitarizar la región o si estamos aún lejos de alcanzar el objetivo del Acuerdo de Paz (Esquipulas I y II) que concebía las fuerzas militares supeditadas al poder civil, autocontenidas y reservadas únicamente para amenazas externas relacionadas con la defensa e integridad del territorio. Asimismo, facilita contar con evidencia que permita alertar sobre posibles escaladas de conflicto en el contexto de una región que mantiene altos niveles de fragilidad estatal, democrática y el Estado de derecho, esto con el fin de evitar repetir la historia del conflicto armado de las décadas de 1960-1980.

El principal objetivo de este artículo es analizar si el proceso de desmilitarización plasmado en los Acuerdos de Paz de Centroamérica se ha cumplido en Guatemala, Honduras, El Salvador y Nicaragua, en el marco de la crisis de inseguridad que viven en estos países.

Por su parte, los objetivos específicos son los siguientes: (1) Explicar el rol histórico de las fuerzas militares como actores protagónicos en la conflictividad de Centroamérica. (2) Describir el proceso de desmilitarización promovido desde la década de los noventa en el marco del proceso de pacificación de Centroamérica. (3) Examinar los recursos económicos y humanos, así como las tareas actuales de las Fuerzas Armadas (FF.AA.) de Guatemala, El Salvador, Honduras y Nicaragua, con el propósito de evidenciar si se ha cumplido o no con lo pactado en los Acuerdos de Paz en esta temática.

Para lograr estos objetivos, el artículo está estructurado en cuatro secciones. La primera, el marco metodológico que señala los principales métodos de recolección y análisis de información utilizados. La segunda, el marco referencial que expone los principales enfoques teóricos para analizar el papel de las fuerzas 
militares en Centroamérica. Una tercera sección se centra en exponer los principales resultados de la investigación en torno a la evolución histórica de la cuestión militar en Centroamérica, la inseguridad y el rol de las fuerzas militares en el nivel nacional y regional, así como un análisis de las funciones que han cumplido las fuerzas militares en la seguridad interna de estos países en el período 2010-2016. En la cuarta y última sección se sistematizan las principales conclusiones del estudio.

\section{Marco metodológico}

La investigación fue realizada en dos fases: (1) Levantamiento de la información a partir de fuentes secundarias y (2) Validación y ampliación de la investigación por medio de un grupo focal de personas expertas en seguridad de la región centroamericana. El análisis documental de fuentes secundarias abarcó la sistematización de noticias en medios escritos, artículos académicos, libros y revistas científicas sobre el papel, funciones e intervenciones de las fuerzas militares en el período en estudio. La información sistematizada y analizada de esta primera fase fue validada y ampliada en la consulta a 15 personas expertas ${ }^{2}$ centroamericanas en el grupo focal "Seguridad: Balance entre Fuerzas Armadas y Fuerzas Policiales de Centroamérica" realizado el día 23 de junio del 2017 en San José, Costa Rica, en el marco del Proyecto "Jornada de Reflexión: 30 años de la Firma de los Acuerdos de Paz”, ejecutado por la Fundación para la Paz y la Democracia (FUNPADEM). Este artículo resume los principales resultados tanto de la investigación documental, así como de la discusión y análisis de este grupo experto sobre la cuestión militar en Centroamérica después de 30 años de la firma de los acuerdos de Paz en la región.

\section{Marco referencial}

Antes de profundizar en los principales resultados de la investigación acerca del proceso de militarización en Centroamérica, es de suma importancia hacer un breve repaso sobre los diferentes enfoques teóricos, desde las ciencias sociales, sobre el papel de las fuerzas militares en una sociedad. Héctor Rosada, citando a Fernando Bustamante (1999, pp. 30-31) hace una descripción de siete modelos teóricos sobre el fenómeno del militarismo: organizacional-psicosocial, instrumentalista, teoría de la modernización, corporatista, élite orgánica estatista, estratégica-globalista y funcionalismo teleológico (tabla1).

2 Ver apéndice 1 
El primero, el organizacional-psicosocial (Ellis y Moore, 1974; Foucault, 1983; Stimson y Bundy, 1949; Stoyffer, 1949) atribuye al ejército un modelo organizacional de diferente naturaleza a la de la sociedad civil, por lo cual los individuos civiles que quieran formar parte del ejército deben pasar por un proceso de resocialización al interior de la organización castrense. Este modelo de organización se caracteriza por relaciones autoritarias donde prácticamente anulan el sentido civil ${ }^{3}$ y democrático del individuo.

El segundo enfoque es el instrumentista (Huntington, 1968; Nun, 1969; Rojas, 1975; Véliz, 1967) y señala que los militares son un "instrumento" y son utilizados por grupos organizados para imponer sus intereses políticos. Este enfoque desconoce que el ejército tiene sus propias posiciones o intereses; al contrario, son instrumentos de un poder externo dominante, al cual se pueden adherir voluntariamente o ser producto de este grupo hegemónico, principalmente de naturaleza política.

El corporatista o corporativista (Lievwen, 1960; Lievwen, 1964; Stepan, 1988) defiere considerablemente del enfoque instrumentista, ya que se orienta a reconocer que los grupos militares poseen sus propios intereses. Es decir, los consideran actores políticos y grupos de interés con posibilidad de establecer alianzas con otros actores para defender o anteponer sus intereses institucionales.

El cuarto enfoque señalado es la teoría de la modernización expuesta por O’Donell $(1972,1979)$ y Stepan (1988). Esta se enfoca en el rol de los grupos militares en el proceso de transición del autoritarismo a la democracia y en las limitaciones que ellos mismos imponen a la consolidación de los regímenes democráticos. O'Donell (1972) resalta el papel de las fuerzas militares como mecanismos de coerción y represión sobre una amenaza social en perjuicio de instituciones políticas y democráticas, y de la sociedad civil (Bulcourf; Reina, s. f).

El enfoque de élite orgánica estatista, impulsado por el autor Stepan (1988), se centra en que las fuerzas militares son un aparato del Estado y no un grupo social, por lo cual sus acciones responden a la existencia de un proyecto político. Sin embargo, resalta que son actores conscientes, que son capaces de definir y priorizar sus propios intereses y no deben ser reducidos a ser simples "instrumentos" como lo propone el enfoque instrumentista, pues responden al Estado porque son parte del mismo. En este contexto, los proyectos reformistas

3 Carreras (1996, p 10) amplia en este sentido haciendo alusión que la institución militar no es compatible con los derechos humanos. Señala que casi todos los soldados que participaron en una matanza de indígenas en Guatemala, habían sido graduados de cursos de derechos humanos. El entrenamiento militar no hace posible que las bases sobre los cuales se crea la educación de derechos humanos sean eficientes. 
serán aceptados siempre y cuando no se ponga en amenaza la seguridad nacional del Estado (Finer, 1962; Horowitz y Trimberger, 1976; Rouquié, 1982; Stepan, 1973). En otras palabras, la sociedad y su sistema socioeconómico serán aceptados y defendibles, siempre y cuando la conflictividad social no llegue a convertirse en una amenaza perceptible para la seguridad nacional, pues son actores neutrales cuya ética los obliga a defender las bases del Estado contra cualquier amenaza.

El funcionalismo teleológico o del finalismo causal (Johnson, 1964; Lucham, 1971; Pye, 1962; Stepan 1988) se centra en que la función principal de las fuerzas militares es mantener el orden establecido o la construcción de un orden mejor, según un destino manifiesto de interés general.

Y como sétima teoría, el realismo estratégico define que la geopolítica es el componente principal para explicar las formas de conducta y los roles asumidos por las fuerzas militares (Rosada, 1999).

Tabla 1 Resumen de los enfoques teóricos sobre las fuerzas militares por Bustamante

\begin{tabular}{ll}
\hline \multicolumn{1}{c}{ Enfoque teórico } & \multicolumn{1}{c}{ Principal característica de las fuerzas militares } \\
\hline Organizacional-psicosocial & Son incompatibles con la vida civil. \\
\hline Instrumentalista & $\begin{array}{l}\text { No tienen intereses propios, son instrumentos utilizados } \\
\text { por un poder externo dominante. }\end{array}$ \\
\hline Corporatista o corporativista & $\begin{array}{l}\text { Tienen sus propios intereses, por lo cual es un grupo polí- } \\
\text { tico o grupo de interés. }\end{array}$ \\
\hline Modernización & $\begin{array}{l}\text { Son incompatibles con regímenes democráticos, pues son } \\
\text { característicos de regímenes autoritarios. }\end{array}$ \\
\hline Elite orgánica estatista & $\begin{array}{l}\text { Son parte del Estado y su único interés es defender las ba- } \\
\text { ses del Estado ante cualquier amenaza externa o interna. }\end{array}$ \\
\hline Teleológica-funcional & $\begin{array}{l}\text { Su función principal es mantener el orden establecido o la } \\
\text { construcción de un orden mejor según un destino mani- } \\
\text { fiesto de interés general. }\end{array}$ \\
\hline Estratégica-globalista & $\begin{array}{l}\text { La geopolítica es el componente principal para explicar } \\
\text { las formas de conducta y los roles asumidos por las fuer- } \\
\text { zas militares. }\end{array}$
\end{tabular}

Nota: Elaboración propia a partir de la información obtenida de Rosada (1999). 
Tomando en consideración los enfoques teóricos sobre las fuerzas militares y con el fin de realizar un mejor análisis de la situación centroamericana, se han tomado, como principal marco referencial de este artículo, las premisas señaladas en los enfoques organizacional-psicosocial, modernización, corporatista y elite orgánica estatista. La selección de estos cuatro enfoques teóricos para este marco referencial se debe a que la región centroamericana posee características particulares que, de una u otra manera, son abarcadas por estas cuatro orientaciones teóricas:

1. Guatemala, Honduras, El Salvador y Nicaragua sufrieron alrededor de tres décadas de gobiernos de tutela militar autoritarios (1960-1986-7), por lo cual existía un protagonismo militar en lo político y lo civil en detrimento de la democracia (Orozco, 2003). Esa característica está abarcada por el enfoque modernización y por el corporatista.

2. Los cuatro países tienen Estados de derecho en consolidación con una incipiente vida democrática (la cual fue retomada a partir de 1990). Premisa abordada por el enfoque de modernización.

3. En las guerras civiles de la década de 1980, en estos cuatro países se identificaron una serie de violaciones a los derechos humanos de sus propios compatriotas, a manos de las fuerzas armadas. Característica que se puede explicar desde el enfoque teórico organizacional-psicosocial.

4. En la década de 1960-1980 las fuerzas militares visualizaron como "amenaza" los intereses de sus propios pueblos (Rivera, 2017), pues la conflictividad social fue considerada como una amenaza interna. Esta premisa es abordada por el enfoque teórico de elite orgánica estatista.

En efecto, teniendo en cuenta el papel desfavorable que habían asumido las fuerzas militares en estos países antes y durante las guerras civiles, los gobiernos de estos cuatros países alcanzaron un compromiso para el debilitamiento de sus fuerzas armadas. Esto, en el entendido de que eran una amenaza a sus procesos de paz y que no eran compatibles con la vida política y social, las cuales querían fortalecer en la década de 1990, una vez finalizadas las guerras internas (Rivera, 2017).

\section{Resultados}

Expuestos los fundamentos teóricos del análisis, es esencial que, al discutir de remilitarización en una zona específica, se realice una contextualización 
histórica del rol del ejército en esa área geográfica. Esto, debido a que no es lo mismo referirse a la remilitarización en una región de estabilidad política, que en otra donde el proceso de transición del autoritarismo a democracia plena aún no ha finalizado, como es el caso específico de Centroamérica. Por lo cual, estudiar el resurgimiento del fenómeno militar en una democracia consolidada podría ser un ejercicio esencialmente académico. Investigar la remilitarización en sociedades que han sido marcadas por la violencia generada por los ejércitos, que por décadas tutelaron "democracias de fachada", es un factor esencial para pensar el futuro de la democracia en la región centroamericana.

La historia de Centroamérica no es de democracia sino de autoritarismos de tutela militar (Orozco, 2003). Por lo tanto, es necesario hacer una relectura histórica de la evolución de estas democracias en transición desde mediados del siglo pasado hasta la actualidad, con el fin de caracterizar el proyecto militar que se tenía antes de los acuerdos de paz y el proyecto militar al que anhelaba los acuerdos de paz, y su debido -o no-cumplimiento en la actualidad.

Se han identificado tres períodos que explican la evolución histórica de la cuestión militar en la región centroamericana y que van de la mano con sus procesos de democratización:

a) Protagonismo de las Fuerzas Armadas y tutela militar en Centroamérica: De la década de los sesenta hasta inicios de los ochentas del siglo $\mathrm{XX}$.

b) La promesa de la paz: La nueva integración, la promesa democrática y el restablecimiento del equilibrio cívico - militar, de finales de la década de los ochenta del siglo XX hasta inicios del siglo XXI.

c) Regreso de la violencia en democracias aún inconclusas: la crisis de inseguridad de la primera década del siglo XXI y el fortalecimiento de las fuerzas militares.

a. Protagonismo de las Fuerzas Armadas y tutela militar en Centroamérica: De la década de los sesenta hasta inicios de los ochentas del siglo $X X$.

A partir de la década de los sesenta del siglo anterior, la región centroamericana, con excepción de Costa Rica (Lehoucq, 2015), inició el período más autoritario de su historia, el cual duró aproximadamente tres décadas (Figueroa, 1994; Orozco, 2003). Este período estuvo caracterizado por golpes militares, 
regímenes dictatoriales, procesos electorales poco transparentes, el surgimiento de grupos paramilitares y las repetidas violaciones a los derechos humanos y delitos de lesa humanidad cometidos por las fuerzas militares, estos últimos encargados de tutelar los gobiernos "democráticos" de fachada, represivos e impuestos por élites políticas y grupos de interés (Figueroa, 1994, pp. 877-879).

Las fuerzas militares pactaron con los actores políticos, pasando de ser actores tradicionalmente de la política defensa (defender la soberanía y al territorio de amenazas externas) a actores de la política interna. De hecho, los conflictos militares en Centroamérica fueron internos, sus principales actores fueron los ejércitos que respaldaron los gobiernos dictatoriales, por un lado, y por el otro, grupos conformados por civiles que estaban disconformes con el gobierno de turno (Rosada, 1998, p. 15).

Lejos de los preceptos de las teorías clásicas de seguridad nacional que señalan que el papel de los ejércitos es principalmente la defensa del Estado (conformado por territorio, gobierno y población) de las amenazas externas, los ejércitos centroamericanos defendieron al "Estado", entendido como el régimen de turno, de una amenaza interna: la oposición política. Esto lo refleja el autor centroamericano Manuel Orozco (2003, p. 19) al señalar que "la historia política de Centroamérica ha estado plagada de dictaduras y gobiernos militares... Cada uno de esos dictadores utilizó alianzas con los militares para asegurar su posición de poder y autoridad. En países como Guatemala y El Salvador, los militares creaban sus propios partidos formados por oficiales retirados”. Esta alianza perversa entre élites políticas y las fuerzas militares para acceder y perpetuarse en el poder, imponiendo dictaduras o regímenes militares, ocurrió en Guatemala, El Salvador, Nicaragua, Honduras y Panamá.

Ante la represión de estas élites políticas-militares, la oposición se organizó y protestó por medio de movimientos sociales que frecuentemente eran reprimidos de manera violenta por las fuerzas militares (Orozco, 2003), pues representaban una amenaza a su proyecto político.

Como consecuencia en este período, surgieron grupos guerrilleros. La mayoría eran miembros de partidos derrocados por medio de golpes de Estado. En este período se conformó una serie de organizaciones opositoras, entre las más emblemáticas: la Unidad Revolucionaria Nacional Guatemalteca (URNG) en Guatemala, la Unificación Democrática en Honduras, el Frente Farabundo Martí para la Liberación Nacional (FMLN) en El Salvador y en Nicaragua se conformó el Frente Sandinista de Liberación Nacional (FSLN). 
Durante este período oscuro de la historia de Centroamérica, el enfrentamiento entre militares y civiles registró más de 300.000 muertes de personas y 1.000.000 de desplazados (Torres-Rivas, 1997 p. 89). Además de las pérdidas humanas, se postergó aún más la llegada de democracias funcionales y sostenibles, por lo cual en Centroamérica lo que hubo, hasta la década de 1980, fueron regímenes autoritarios con mayores o menores niveles de apertura.

\section{b. La promesa de la paz: La nueva integración, la promesa democrática y el restablecimiento del equilibrio cívico - militar, de finales de la década de los ochenta del siglo XX hasta inicios del siglo XXI.}

Luego de alrededor de tres décadas de guerras civiles ${ }^{4}$, inestabilidad política y deterioro de sus economías, a finales de 1980 los países centroamericanos inician el camino para alcanzar la anhelada paz firme y duradera en el marco del paulatino debilitamiento del socialismo soviético y su influencia en la región (FUNPADEM, 2011, p. 82).

A partir de mediados de la década de los ochenta inician una serie de negociaciones políticas y diplomáticas para poner fin a los conflictos militares en la región lideradas por el grupo Contadora ${ }^{5}$ (Murillo, 2003, p. 56) y el grupo de Apoyo que culminan con la firma de los Acuerdos de Paz de Esquipulas (Rosada, 1998, pp.19-20). Este proceso de pacificación inició alrededor del año 1984 y se consolidó en las firmas de Esquipulas I (1986) y Esquipulas II (1987) promovidas por los expresidentes Óscar Arias de Costa Rica y Vinicio Cerezo de Guatemala. Estos acuerdos fueron principalmente negociados entre los gobiernos y la insurgencia armada, y proponían un proyecto militar basado en los siguientes principios: el desarme de los grupos combatientes, un equilibrio cívico-militar, disminución del poder militar y la consolidación de gobiernos democráticos y Estados de derecho.

Esquipulas I resalta que la paz firme y duradera en Centroamérica depende de la construcción de democracias plenas, participativas y pluralistas en la región

4 Rojas Aravena (FUNPADEM, 2011, p. 182) indica al respecto "A esto deben agregarse los desafíos propios de sociedades post-conflicto: 1)graves debilidades institucionales, 2) una trama compleja de recuperación económica ligada a cambios en la globalización, con débiles mecanismos de cohesión social, 3) debilidades en la legitimidad democrática, 4) un sistema político debilitado, con partidos políticos sin apoyo ciudadano, y con alta desconfianza, 5) reducidas capacidades de aplicar el Estado de Derecho, 6) bajos grados de profesionalización policial ; y 7) la presencia considerable y creciente en diversas áreas y zonas de corrupción e impunidad".

5 Instancia multilateral integrada por México, Colombia, Panamá y Venezuela con el fin de promover conjuntamente la paz en Centroamérica desde 1983. 
(Declaración de Esquipulas I, 1986). En esta declaración se toma el acuerdo por parte de todos los países de la región de firmar el "Acta de Contadora para la Paz y la Cooperación en Centroamérica”. Esta Acta señala, entre varias cosas, que para lograr la paz en la región es necesario adoptar medidas nacionales en materia de seguridad y desarme, indica además que la superioridad militar como objetivo político de los Estados constituye no solo una amenaza a la seguridad nacional, sino también un factor desestabilizador en la región ${ }^{6}$. Igualmente, en este convenio regional se expresaba el compromiso de "detener la carrera armamentista en todas sus formas" y establecer límites máximos de armamento y número de militares, aumentar el control y asegurar su reducción (Capítulo 3, Sección 2, artículo18).

Un año después, en 1987, los países centroamericanos volvieron a expresar su compromiso de establecer la paz firme y duradera en la región por medio de la firma de Esquipulas II. Este acuerdo presentaba los mecanismos aprobados por los países para lograr el cese de las hostilidades y la reconciliación nacional: diálogo, amnistía y la Comisión Nacional de Reconciliación. Al mismo tiempo, promovía la democratización de los países, asegurando el respeto de las libertades, pluralismo político y elecciones libres con observancia electoral interna como externa. Y se acordaba que, por medio de la mediación del Grupo Contadora, se proseguía con las negociaciones en materia de seguridad, verificación, control y limitación de armamento (Declaración de Esquipulas II, punto 7).

No hay duda de que a partir de la firma de los Acuerdos de Paz, una nueva etapa se visualizaba en la región centroamericana, para la consolidación de la paz y la democracia. Aportando a este objetivo, en este período nace el Sistema Integración Centroamericana (SICA) ${ }^{7}$. De hecho, el proceso de pacificación no solo apaciguó los conflictos internos de los países, sino también el relanzamiento de la idea de la integración en la región como un instrumento que coadyuvara a la paz y la democracia en Centroamérica. En el primer lustro de los años noventa, el SICA impulsó dos instrumentos que promovían el proceso de paz, las relaciones cívico-militares y un nuevo modelo de seguridad apropiado para la realidad de la región, con el fin de superar el modelo de seguridad nacional que había persistido en el siglo anterior (Matul y Segura, 2010, pp.6-7).

El primer instrumento fue el Protocolo de Tegucigalpa (1991) que reforma la Carta a la Organización de Centroamérica (ODECA) de 1951. En este documento se plasma la creación del SICA y define como su principal objetivo

6 Premisa abordada por el enfoque teórico modernización de O’Donell (1972).

7 La institucionalidad formal de la integración en la región había iniciado en la segunda mitad del siglo $\mathrm{XX}$, pero por la conflictividad que caracterizada la región en las décadas de los sesentas-ochentas se había estancado (Matul \& Segura, 2010, p. 6) 
la "realización de la integración de Centroamérica, para constituirla como región de paz, libertad, democracia y desarrollo" (Art. 3, Protocolo de Tegucigalpa, 1991). Este protocolo fue suscrito por Guatemala, Honduras, El Salvador, Nicaragua, Costa Rica y Panamá; y buscaba: "concretar un nuevo modelo de seguridad regional sustentado en un balance razonable de fuerzas, el fortalecimiento del poder civil, la superación de la pobreza extrema, la promoción del desarrollo sostenido, la protección del medio ambiente, la erradicación de la violencia, la corrupción, el terrorismo, el narcotráfico y el tráfico de armas" (Art. 3.b Protocolo de Tegucigalpa, 1991).

Este último enunciado del Protocolo de Tegucigalpa ilustra muy bien la esencia de la nueva etapa que empezaba a forjarse en Centroamérica, especialmente en la creación de un nuevo modelo de seguridad sustentado en el restablecimiento del equilibrio militar-cívico, cuyos principios básicos fueron el "... balance razonable de fuerzas $[y]$ el fortalecimiento del poder civil...".

Este nuevo modelo de seguridad que se empieza a visualizar en el Protocolo de Tegucigalpa se fortalece en el segundo instrumento regional de este proceso, el Tratado Marco de Seguridad Democrática (TMSD) de 1995 (Meléndez, 2009, p. 34). El TMSD define la esencia del nuevo modelo de seguridad que se gesta dentro de la integración centroamericana: la seguridad democrática. La seguridad democrática "tiene su razón de ser en el respeto, promoción y tutela de todos los derechos humanos, por lo que sus disposiciones garantizan la seguridad de los Estados centroamericanos y sus habitantes, mediante la creación de condiciones que les permita su desarrollo personal, familiar y social en paz, libertad y democracia" (TMSD, 1995, p. 2). Lo más sobresaliente e innovador de este instrumento es que señala, como uno de sus principios, la subordinación de las fuerzas armadas al poder civil (Artículo 2.c TMSD, 1995).

La década de los noventas fue muy fructífera en los esfuerzos de la desmilitarización de la región (Cordero, Zeledón 1994; Rojas, 1996) No solo porque se crearon nuevos instrumentos regionales que vinieron a fortalecer este proceso, sino también porque en las nuevas constituciones políticas se plasmaron el principio de la subordinación de las fuerzas armadas al poder civil y la necesidad de limitar el accionar de las fuerzas militares a temas concretos de seguridad nacional. Ejemplo de ello es la Constitución Política de la República de Guatemala (1993) que incorpora el principio de subordinación de las fuerzas armadas al poder civil, así como la supremacía del populus potestatem. "El poder proviene del pueblo. Su ejercicio está sujeto a las limitaciones señaladas por esta Constitución y la ley. Ninguna persona, sector del pueblo, fuerza armada o política, puede arrogarse su ejercicio" (Art. 152, Constitución Política de Guatemala). 
Estos países se comprometieron a alcanzar un equilibrio cívico y militar, para lo cual su primer paso fue la creación o fortalecimiento de cuerpos policías nacionales civiles (PNC), con base en los principios de seguridad pública con enfoque de derechos humanos. Estos cuerpos policiales reemplazarían a las fuerzas militares en las tareas de seguridad interna y limitarían el actuar de estas, a situaciones muy concretas, especialmente relacionadas con la defensa de la soberanía y con la lucha contra amenazas externas. Disminuyendo considerablemente el poder de influencia de las fuerzas armadas en estos países.

Si bien, existían cuerpos policiales en todos los países de la región antes de las guerras civiles, por el empoderamiento de las fuerzas militares estas policías nacionales fueron desplazadas de sus funciones ordinarias. En algunos casos, estos cuerpos policiales desaparecieron por completo como en Guatemala y El Salvador, y en otros fueron transformadas en simples guardas civiles, al servicio de las fuerzas militares como los casos de Nicaragua y Honduras (Cuadra, 2017). No es sino hasta la década de los años noventa cuando las Policías Nacionales Civiles surgen de una manera renovada y basadas en el espíritu de los Acuerdos de Paz (tabla 2).

Tabla 2. Policías Nacionales Civiles de Guatemala, Honduras, El Salvador y Nicaragua: año de creación y misión

\begin{tabular}{cll}
\hline País & $\begin{array}{c}\text { Año de } \\
\text { creación }\end{array}$ & \multicolumn{1}{c}{ Misión } \\
\hline Guatemala & 1996 & $\begin{array}{l}\text { Proteger la vida y los bienes de todos, el ejercicio de sus dere- } \\
\text { chos y obligaciones por medio de la prevención, investigación } \\
\text { y el combate del delito para contribuir a crear un ambiente de } \\
\text { paz y armonía. }\end{array}$ \\
\hline & $\begin{array}{l}\text { La Policía Nacional de Honduras es una institución profesio- } \\
\text { nal y permanente del Estado, apolítica en el sentido partidista, } \\
\text { de naturaleza puramente civil, encargada de velar por la con- } \\
\text { servación del orden público, la prevención, control y comba- } \\
\text { te al delito; protección de la seguridad de las personas y sus } \\
\text { bienes; ejecutar las resoluciones, disposiciones, mandatos y } \\
\text { decisiones legales de las autoridades y funcionarios públicos, } \\
\text { todo con el estricto respeto a la ley en general y a los derechos } \\
\text { humanos. }\end{array}$ \\
\hline
\end{tabular}




\begin{tabular}{ccl}
\hline País & $\begin{array}{c}\text { Año de } \\
\text { creación }\end{array}$ & \multicolumn{1}{c}{ Misión } \\
\hline \multirow{3}{*}{ El Salvador } & 1993 & $\begin{array}{l}\text { Garantizar el libre ejercicio de los Derechos y Libertades de } \\
\text { las personas, la seguridad, la tranquilidad y el orden, previ- } \\
\text { niendo y reprimiendo el delito, con estricto respeto a los de- } \\
\text { rechos humanos, integrando el compromiso del personal y la } \\
\text { participación de la población, contribuyendo al fomento del } \\
\text { estado de derecho y desarrollo integral del país. }\end{array}$ \\
\hline & $\begin{array}{l}\text { La promoción, protección y defensa de la seguridad de la vida } \\
\text { y de la propiedad y del libre ejercicio de los derechos de la } \\
\text { población sin discriminación alguna, cumpliendo y hacien- } \\
\text { do cumplir la ley; previniendo, investigando y esclareciendo } \\
\text { acciones contra la seguridad individual y pública; auxiliando } \\
\text { a los órganos jurisdiccionales a fin de lograr una eficiente ad- } \\
\text { ministración de justicia, la armonía social y el fortalecimien- } \\
\text { to del estado de derecho; contribuyendo a la educación de la } \\
\text { ciudadanía en el respeto de las instituciones del Estado, la } \\
\text { autoridad y sus agentes; y coadyuvando a la gobernabilidad } \\
\text { del país y el mantenimiento del orden social necesario para el } \\
\text { desarrollo sostenible de la nación. }\end{array}$ \\
\hline
\end{tabular}

Nota: Elaboración propia a partir de la información institucional de cada cuerpo policial: PNC Nicaragua (s. f.), PNC Honduras (2018), PNC El Salvador (s. f.) y PNC Guatemala (2014).

En la década de los noventas se inicia la transición política de regímenes autoritarios tutelados por los cuerpos militares a una nueva forma de gobierno de alternancia en el poder, por medio de elecciones libres. Es así como se dan los primeros pasos para el fortalecimiento de la democracia por medio de elecciones libres, transparentes y participativas. Asimismo, es durante esta década donde surgen los Concejos Supremos Electorales (anteriormente Concejos Electorales) como una institución independiente encargada de tutelar estos procesos electorales de manera transparente (Orozco, 2003).

Otra característica propia de este período es el empoderamiento de la ciudadanía, no solo para motivarla a votar sino a organizarse para la vigilancia de estos procesos electorales. Es así cómo, en varios países de Centroamérica, surgen organizaciones no gubernamentales que se vuelven en veedores electorales de la incipiente vida democrática de estos países (Orozco, 2003).

Según la experta nicaragüense Elvira Cuadra (2017), la década de los noventa se caracterizó por ser el período dorado de la desmilitarización de la región, se reconoce un avance importante en el fortalecimiento del poder civil sobre el militar, el fortalecimiento de las policías nacionales civiles y la construcción de 
regímenes democráticos, cambios liderados por gobiernos comprometidos con el espíritu de los Acuerdos de Paz.

\section{c. Regreso de la violencia en democracias aún inconclusas: La crisis de inseguridad de la primera década del siglo XXI y el fortalecimiento de las fuerzas militares}

Después de la firma de los Acuerdos de Paz, los índices de violencia y criminalidad se disminuyeron considerablemente, en comparación con los años de guerra civil. Durante la década de los noventa, los países centroamericanos registraban tasas de homicidios dolosos entre los 4-40 homicidios por cada 100.000 habitantes, donde Costa Rica, Panamá y Nicaragua eran los países que disfrutaban de mejores niveles de seguridad (Cuadra, 2017)

Sin embargo, los esfuerzos para lograr la pacificación de la región, el fortalecimiento de la democracia y la consolidación de los Estados de derecho se ven cercenados con el surgimiento de nuevas amenazas internas, principalmente relacionadas con las violencias del crimen organizado y la delincuencia (Urcuyo, 2009, p. 44).

En las décadas 1970 y 1980, mucha población centroamericana migró a los Estados Unidos huyendo de la cruda violencia y persecución política que caracterizaba esa época. No obstante, una vez que las guerras civiles terminaron, gran cantidad de estos grupos migrantes (algunos de "segunda generación") regresaron voluntaria o involuntariamente (deportaciones masivas) a estos países (ONUDD, 2007, p. 63).

Las deportaciones masivas desde los Estados Unidos fueron resultado de una política interna para controlar las pandillas en el país. Esto, debido a que algunas de las personas migrantes procedentes de Centroamérica eran parte de las ya populares pandillas estadounidenses, principalmente en ciudades como Los Ángeles. Por lo cual, ante la impotencia de ese país por controlar y corregir estas conductas antisociales, el gobierno estadounidense decide "regresarlos" a sus países de origen, principalmente a El Salvador, donde constituyen las maras "salvatrucha" o MS 13 y la mara 18 o M18, ambas rivales (ONUDD, 2007, p. 65). Esta condición, agregada a la difícil situación socioeconómica y las escasas oportunidades laborales que se pueden tener en un país devastado por una guerra civil de tres décadas, contribuyó para que los problemas sociales surgieran y se agravaran en el tiempo. 
Aunado al incremento del tráfico ilícito de drogas y armas, en el siglo XXI los índices de violencia y criminalidad se incrementan exponencialmente en la región. La tasa promedio de homicidios de los países del triángulo norte empezó a oscilar entre 70 y 100 homicidios por cada 100.000 habitantes $^{89}$. Centroamérica se empieza a ubicarse como una de las regiones más violentas del mundo, sin tener un conflicto armado declarado. Arias (2016) señala que "Centroamérica fue en el 2015 nuevamente la región más violenta del mundo La esperanza de la paz que trajeron los Acuerdos de Esquipulas al final del Siglo pasado, parece desvanecerse conforme avanza el nuevo siglo" (p. 105).

En este período, la violencia relacionada al crimen organizado floreció en un contexto centroamericano donde el estado de derecho aún estaba en construcción y los escándalos por corrupción en las cúpulas de los gobiernos eran cada vez más comunes. De hecho, Hilton y Montalvo (citados por Arias, 2016) afirman que existe una amplia evidencia acerca de las amenazas del crimen y la violencia a la calidad de la democracia y la gobernabilidad.

Es más, estudios como los de Zinecker (2012) señalan que, a pesar de los esfuerzos de los países de la región centroamericana, las democracias aún no existen. Lo que existe en estos países de la región es lo que Zinecker denomina regímenes híbridos, es decir, "no gobierna más una dictadura militar y las elecciones democráticas son la regla. No obstante, no es una democracia todavía, ya que predomina la exclusión política, falta el estado de derecho y no funcionan algunas de las instituciones estatales. Allá, donde las instituciones estatales no funcionan permanentemente o se caracterizan por tener un mal funcionamiento, no se puede hablar de un régimen democrático, pues una democracia que no funciona no es una democracia" (Zinecker, 2012, p. 7).

En este período ocurre, de nuevo, una gran oleada de migración de personas de Guatemala, Honduras y El Salvador a países como Estados Unidos o al sur de Centroamérica (Costa Rica y Panamá) en busca de lugares seguros para escapar de la violencia sistemática producida por organizaciones del crimen organizado y las pandillas ("maras"), que prácticamente tienen el control total de territorios donde está ausente el Estado en estos países del norte de la región.

Los gobiernos de la región, desesperados, empezaron a tomar medidas populistas como la implementación de políticas o planes basados en la represión ("mano dura"), el fortalecimiento de las fuerzas militares, principalmente en

8 Según la OMS, una tasa de homicidio mayor a 10 es considerado como epidemia.

9 Para esa época, las excepciones son Costa Rica, Nicaragua y Panamá que poseen tasas de homicidios entre 8 y 12 homicidios por cada 100.000 habitantes. 
operativos en conjunto con las PNC, para controlar ciertos territorios y la militarización de la seguridad ciudadana con el nombramiento de exmilitares como Ministros de Seguridad o jefes de las Policías Nacionales Civiles (específicamente en El Salvador y Nicaragua). Con todas estas medidas, se rompió el compromiso asumido en los Acuerdos de Paz, en el Protocolo de Tegucigalpa y el TMSD sobre la subordinación militar-civil y la prohibición de nombramiento de militares o exmilitares en cargos políticos o públicos en estos países.

El fracaso de estas políticas de "mano dura" se hizo evidente a finales de la primera década del siglo XXI, cuando la tasa de homicidios de estos países no disminuyó, sino que, al contrario, siguió aumentado desmedidamente, así como la tasa de hacinamiento carcelario. Ejemplo de ello es El Salvador, donde a los centros penitenciarios se enviaba a cualquier persona sospechosa de ser miembro de las "maras", sospechas que incluían tener tatuajes, uso de ciertas jergas, coincidir en ciertos horarios de reunión en la vía pública, entre otros. Ello ocasionó que las instituciones carcelarias devinieran en "escuelas" del crimen (Sampó y Bartolomé, 2014). De la misma manera, la ausencia de medidas que atacaran los orígenes estructurales del fenómeno de las maras también contribuyó al fracaso de estas políticas.

Esta situación no solo amenazó el proceso de consolidación de regímenes democráticos, sino principalmente influyó en la construcción de un nuevo proyecto militar y provocó un retroceso a lo alcanzado en la década de los noventas (Cuadra, 2017). Este retroceso se hace evidente cuando se estudian los principales acontecimientos en los países centroamericanos relacionados con el balance cívico-militar. Este retroceso se caracterizó por:

- Fortalecimiento de las fuerzas militares a cuestas del debilitamiento de las policías civiles nacionales.

- Involucramiento de las fuerzas militares en la seguridad ciudadana y en la vida política de los países.

\section{Fortalecimiento de las Fuerzas Militares a cuestas del debilitamiento de las policías nacionales}

A pesar de que, en la década de los noventa los gobiernos centroamericanos realizaron grandes esfuerzos para restablecer el equilibrio cívico militar y la creación de las policías nacionales civiles, no fueron suficientes para hacer 
frente a las nuevas amenazas del crimen organizado ${ }^{10}$ y de la delincuencia que amenazan a la región (Rojas, 2012)

Las PNC no tuvieron el apoyo necesario tanto de recursos financieros como humanos para fortalecerlas y profesionalizarlas, y en su mayoría dependían de la cooperación internacional para capacitar a oficiales de estos cuerpos policiales (Cuadra, 2017). De hecho, personas expertas han señalado que muchas de estas instituciones policiales fueron creadas e integradas por el mismo personal retirado de las fuerzas armadas de esa época (FUNPADEM, 2017). Esta condición puede haber influido en no lograr un verdadero fortalecimiento civilista de estos cuerpos policiales.

Aunado a lo anterior, las PNC de Guatemala, Honduras y El Salvador empezaron a ser protagonistas de escándalos de corrupción, desde la introducción del crimen organizado hasta la participación de oficiales en las pandillas "maras", así se incrementó el sentimiento de desconfianza y poca legitimidad hacia este cuerpo policial (Cuadra, 2017). Ante débiles y deslegitimizadas PNC sin la capacidad de controlar estas nuevas amenazas internas y los aumentos constantes en los índices de criminalidad, la población empezó a pedir "mano dura". Por tal razón y ante la "necesidad" de poner orden, una de las soluciones de estos gobiernos fue devolver al escenario de seguridad interna a las fuerzas militares.

Otro argumento resucitador de las fuerzas militares en los países del Triángulo Norte fue el inicio de la "guerra contra las drogas", promovida principalmente por Estados Unidos para combatir el tráfico de drogas y sus delitos relacionados, en la que involucraba a todos los países de la región centroamericana. El enfoque principal de la "guerra contra las drogas" fue la implementación de medidas duras y represivas, por lo que surgen, en estos países centroamericanos, políticas de seguridad como "Cero Tolerancia", "Plan Mano Dura" y "Plan Súper Mano Dura" en El Salvador; "Cero Tolerancia", "Operación Libertad" y "Libertad Azul" en Honduras y el Plan Escoba en Guatemala (Rivera, 2009). Lo más grave de la situación es que muchas de estas medidas de "mano dura" abarcaban desde el desarrollo de habilidades militares en policías nacionales civiles por medio de entrenamientos financiados por la cooperación internacional, hasta la donación de equipo militar a estos países (Cuadra, 2017).

En la misma línea de fortalecimiento de las fuerzas militares centroamericanas, desde el 2006 al 2016, la región pasó de invertir US\$340.308.308 a

10 Rojas Aravena (2012) señala que la pobreza y la desigualdad que caracteriza a la región centroamericana provocan una mayor conflictividad social y hacen de la región un caldo de cultivo para las actividades del crimen organizado. 
US\$815.572.350, es decir, un 140\% más en presupuesto para defensa en tan solo una década (RESDAL, 2016). Por país, este aumento porcentual en el presupuesto de defensa es más significativo: Honduras registra un aumento de 426\%, seguido de Nicaragua con un 100\%, Guatemala con un 97\% y El Salvador con un aumento porcentual de 37 en el mismo período (tabla 3). Destaca el caso de Honduras, por el gran aumento registrado, a pesar de que durante ese período no se identifica ningún conflicto interno o externo declarado que justifique este crecimiento a nivel de presupuesto en defensa.

Tabla 3. Presupuesto en defensa (en US\$) Centroamérica 2006-2016

\begin{tabular}{lcccccc}
\hline \multicolumn{1}{c}{ País/ Año } & 2006 & 2008 & 2010 & 2012 & 2014 & 2016 \\
\hline EI Salvador & $\$ 106.363 .230$ & $\$ 115.409 .495$ & $\$ 132.874 .110$ & $\$ 144.067 .030$ & $\$ 149.455 .885$ & $\$ 146.139 .840$ \\
\hline Guatemala & $\$ 134.476 .326$ & $\$ 156.210 .263$ & $\$ 159.860 .766$ & $\$ 210.816 .824$ & $\$ 257.962 .025$ & $\$ 264.313 .810$ \\
\hline Honduras & $\$ 63.175 .260$ & $\$ 121.183 .088$ & $\$ 172.194 .128$ & $\$ 188.926 .130$ & $\$ 252.646 .424$ & $\$ 332.560 .070$ \\
\hline Nicaragua & $\$ 36.293 .492$ & $\$ 42.191 .833$ & $\$ 39.644 .293$ & $\$ 65.756 .103$ & $\$ 82.888 .983$ & $\$ 72.558 .630$ \\
\hline Total & $\$ 340.308 .308$ & $\$ 434.994 .679$ & $\$ 504.573 .297$ & $\$ 609.566 .087$ & $\$ 742.953 .317$ & $\$ 815.572 .350$
\end{tabular}

Nota: Elaboración propia. Datos obtenidos de RESDAL (2010, 2012, 2014, 2016) Atlas Comparativo de la Defensa en América Latina y el Caribe.

A lo anterior, hay que sumarle la cooperación internacional que realizan año tras año los países de Estados Unidos (para Guatemala, El Salvador y Honduras) y Rusia (para Nicaragua) en equipamiento y preparación militar a las fuerzas armadas de la región, la cual no se visualiza en ningún indicador económico de estos países.

Con respecto a los efectivos militares, según RESDAL (2016), todos los países de la región centroamericana aumentaron su número de efectivos por cada 100.000 habitantes en el periodo 2008-2016 (tabla 4). El caso más sobresaliente es El Salvador, que pasó de 2,3 efectivos de fuerzas militares por cada 100.000 habitantes en el 2008 a 3,9 en el 2016. En efecto, si se analiza porcentualmente el aumento de la tasa de ese período sería de un $70 \%$ de incremento en El Salvador, $36 \%$ en Honduras, un 24\% en Nicaragua, y un $10 \%$ para Guatemala. 
Tabla 4. Tasa de efectivos de fuerzas militares por cada 100.000 habitantes. Centroamérica 2008-2016

\begin{tabular}{lcccccc}
\hline País/ Año & $\mathbf{2 0 0 8}$ & $\mathbf{2 0 1 0}$ & $\mathbf{2 0 1 2}$ & $\mathbf{2 0 1 4}$ & $\mathbf{2 0 1 6}$ & $\begin{array}{c}\text { Variación } \\
\text { de la tasa }\end{array}$ \\
\hline El Salvador & 2,3 & 2,3 & 2,5 & 3,9 & 3,9 & $+1,6$ \\
\hline Guatemala & 1,0 & 1,0 & 1,0 & 1,4 & 1,1 & $+0,1$ \\
\hline Honduras & 1,4 & 1,1 & 1,3 & 1,9 & 1,9 & $+0,5$ \\
\hline Nicaragua & 1,7 & 1,6 & 1,7 & 1,7 & 2,1 & $+0,4$
\end{tabular}

Nota: Elaboración propia. Datos obtenidos de RESDAL (2016) Atlas Comparativo de la Defensa en América Latina y el Caribe.

Según el Atlas Comparativo de Defensa de RESDAL (2014, citado por Villalobos (2016, p. 3), "si se compara los datos anteriores, con países con conflictos internos como México y Colombia, se puede observar que el aumento porcentual no es proporcional con el de Centroamérica. México, para el período 20102014, registró un aumento de sus efectivos de fuerzas militares de un $2,7 \%$ y Colombia más bien una disminución del 0,03\%".

Dicho fortalecimiento en las fuerzas militares en Centroamérica no se hizo de igual manera para las fuerzas policiales civiles de la región. A pesar, de que uno de los principales mandatos en los Acuerdos de Paz era fortalecer las fuerzas policiales y no las fuerzas militares.

Tabla 5. Tasa de efectivos Policía Nacional no militar por cada 100.000 habitantes. Centroamérica 2008-2016

\begin{tabular}{lcccccc}
\hline \multicolumn{1}{c}{ País/ Año } & $\mathbf{2 0 0 8}$ & $\mathbf{2 0 1 0}$ & $\mathbf{2 0 1 2}$ & $\mathbf{2 0 1 4}$ & $\mathbf{2 0 1 6}$ & Variación \\
\hline Costa Rica & 2,5 & 2,8 & 3,0 & 2,9 & 2,9 & $+0,4$ \\
\hline El Salvador & 2,9 & 3,3 & 2,5 & 3,6 & ND & $+0,7^{*}$ \\
\hline Guatemala & 1,4 & 1,6 & 1,7 & 2,2 & 2,3 & $+0,8$ \\
\hline Honduras & ND & 1,7 & 1,4 & ND & 1,6 & $-0,1$ \\
\hline Nicaragua & 1,7 & 1,8 & 2,2 & 2,2 & ND & $+0,5^{*}$ \\
\hline Panamá & 3,3 & 3,4 & 5,1 & ND & 5,78 & $+1,8$ \\
\hline
\end{tabular}

Nota: Tomado de Base de Datos Estado de la Región (2017).

ND: No disponible.

*La comparación para poder obtener la variación de la tasa se realizó con el último año disponible. 
Como se observa en la Tabla 5, la variación en la tasa de efectivos en las Policías Nacionales no militares (es decir, de policías nacionales civiles) por cada 100.000 habitantes no es significativa y en el caso específico de Honduras, más bien hubo una disminución en los efectivos en el 2016 con respecto al 2010. Si se realiza un comparativo del 2008 al 2016 de las variaciones expresadas en porcentajes de la tasa de efectivos militares y policiales en Guatemala, Honduras, El Salvador y Nicaragua, se puede observar claramente la diferencia en los procesos de fortalecimiento de ambos cuerpos (Tabla 6).

Tabla 6 Variación expresada en porcentaje de la tasa de efectivos militares y policiales en Centroamérica en el período 2008-2016

\begin{tabular}{lcc} 
País/ Año & $\begin{array}{c}\text { Variación en \% de la tasa de efec- } \\
\text { tivos militares por cada } \mathbf{1 0 0 . 0 0 0} \\
\text { hab. }\end{array}$ & $\begin{array}{c}\text { Variación en \% de la tasa de efec- } \\
\text { tivos policiales no militares por } \\
\text { cada 100.000 hab. }\end{array}$ \\
\hline El Salvador & +70 & +24 \\
\hline Guatemala & +10 & +58 \\
\hline Honduras & +36 & -7 \\
\hline Nicaragua & +24 & +30 \\
\hline $\begin{array}{l}\text { Nota: } \text { Elaboración propia a partir del análisis de los datos obtenidos de RESDAL (2016) y el Estado } \\
\text { de la Región (2017). }\end{array}$
\end{tabular}

Cabe resaltar, que otro aspecto en tomar en cuenta es que las policías civiles nacionales también han variado su naturaleza; en los últimos años se ha identificado cómo estos cuerpos policiales han adoptado una naturaleza militar, recibiendo equipo y capacitación de orden castrense (RESDAL, 2014, 2016). Por ello, no sería correcto afirmar que en aquellos países donde se puede observar un aumento de los efectivos policiales signifique el cumplimiento del espíritu de los Acuerdos de Paz, donde se expresaba la intención de "detener la carrera armamentista en todas sus formas" y establecer límites máximos de armamento y número de militares, así como el aumentar el control y asegurar su reducción (Acuerdo de Contadora, Capítulo 3, Sección 2, artículo18). En otras palabras, los cuerpos que se tenían que fortalecer eran PNC con espíritu democrático y civilista y no de índole militar.

Debido a lo anterior, las fuerzas militares han expandido su influencia en la seguridad interna del país, fenómeno denominado como securitización de la seguridad (Santillan, 2012, p. 75). Vuelven a ser las fuerzas militares un actor protagonista en el siglo actual, a pesar del ya comprobado peligro que conlleva el fortalecimiento militar para las nacientes democracias de estos países centroamericanos. 


\section{Involucramiento de las fuerzas militares en la seguridad ciudadana y en la vida política de los países centroamericanos}

Las fuerzas militares no solo han aumentado su presupuesto y sus efectivos sino también sus intervenciones en la vigilancia y control de las calles de los países de la región, ya sea de manera individual o en operaciones "en conjunto" con las policías nacionales civiles (Villalobos, 2016). Muchas de estas intervenciones en materia de seguridad ciudadana u orden público han estado justificadas por la "guerra" contra las pandillas (maras) o la "guerra contra el narcotráfico" (Villalobos, 2016).

Desde el año 2011, diferentes organizaciones como el Centro por la Justicia y el Derecho Internacional (CEJIL, 2011) han realizado llamadas de atención a nivel internacional por el fortalecimiento de la militarización de la región centroamericana, específicamente el papel que han protagonizado las fuerzas militares en la seguridad ciudadana. CEJIL (2011, par. 2) señala lo siguiente:

Contradice lo dispuesto por la Comisión y la Corte Interamericana de Derechos Humanos. ... La Corte ha expresado en su jurisprudencia que los Estados deben limitar al máximo el uso de las Fuerzas Armadas para el control de la criminalidad común o violencia interna, puesto que el entrenamiento que reciben está dirigido a derrotar un objetivo legítimo, y no a la protección y control de civiles. Por su parte, la Comisión Interamericana "en su Informe sobre seguridad ciudadana y derechos humanos-advierte que es indudable que la criminalidad ordinaria - por muy grave que sea" no constituye una amenaza militar a la soberanía del Estado que justifique la participación de militares en este tipo de acciones.

De hecho, en Guatemala el expresidente y general retirado Otto Pérez Molina (2012-2015) impulsó usar los kaibiles "fuerzas especiales del Ejército guatemalteco" para combatir el narcotráfico (CEJIL, 2011), creando en el 2012 una fuerza especial de tarea en sus fuerzas militares para el combate al narcotráfico y el contrabando (El Heraldo, s. f). Este tipo de acciones han continuado, según el Atlas Comparativo de Defensa (RESDAL, 2016), y al 2016 las Fuerzas militares guatemaltecas cuentan con dos unidades especiales de apoyo a la PNC como son los Escuadrones de Seguridad Ciudadana y las Brigadas Militares, que en general se involucran en funciones de orden público y seguridad ciudadana en este país centroamericano (tabla 7).

En El Salvador, siguiendo el espíritu de los Acuerdos de Paz, en el año 1996 se crearon una serie de instituciones para ponerle fin a la militarización de la seguridad ciudadana como fue el Consejo Nacional de Seguridad Pública, la Policía Nacional Civil, la Academia Nacional de Seguridad Pública y la Procuraduría 
para la Defensa de los Derechos Humanos (Cárdenas, 2015). Sin embargo, desde el 2003 se registra un retroceso en esta materia, cuando el entonces presidente Francisco Flores (1999-2004) implementa el "Plan Mano Dura" que permite la colaboración de la PNC y las Fuerzas Militares (Cárdenas, 2015); relación que se ha fortalecido hasta el 2016, según el Atlas Comparativo de Defensa (RESDAL, 2016). Actualmente estas dos instituciones trabajan en conjunto en el Plan de Operaciones Zeus, el cual cuenta con dos comandos especiales entre la PNC y las fuerzas militares que realizan trabajo de apoyo comunitario y antidelincuenciales (tabla 7).

En el caso de Honduras, la situación es similar. De hecho, CEJIL (2011) realizó una llamada de atención a este país centroamericano debido a que, en el 2011, el Congreso Nacional aprobó un decreto para que las fuerzas militares realizaran funciones policiales, decreto que viola lo dispuesto en los Acuerdos de Paz. Esta situación se agrava, cuando en el 2013 se aprueba la creación de la Policía Militar de Orden Público, hecho que generó preocupación en organismos de derechos humanos en este país que calificaron como un "retroceso" en la desmilitarización de la sociedad, iniciada en la década de 1990 (La Nación, 23 de agosto 2013). En enero del 2018, esta Policía Militar fue fuertemente criticada por el Alto Comisionado de las Naciones Unidas para los Derechos Humanos $\Pi(\mathrm{OACNUDH})$ por el uso excesivo de la fuerza en las manifestaciones de grupos opositores en el marco de la crisis electoral de ese país. Esa situación no fue aislada, ya que anteriormente se han registrado una serie de enfrentamientos de este tipo contra el pueblo hondureño (Redacción El Criterio, 8 enero 2018). Actualmente, además de la Policía Militar de Orden Público, dentro de la PNC existe la Unidad Policial TIGRES (tabla 7) que tiene la potestad de pedir apoyo y trabajar en conjunto con las fuerzas militares de Honduras (RESDAL, 2016).

En el caso de Nicaragua, en el 2013 inició un Plan de Seguridad Ciudadana basado en el patrullaje de fuerzas combinadas entre Policía y Ejército (La Prensa, 16 de octubre, 2013). Ese plan de seguridad se ha mantenido en los últimos años, a pesar de que en este país las cifras reportadas de criminalidad son muy bajas. En efecto, las fuerzas militares de Nicaragua realizan una serie de funciones de orden público que van desde la lucha contra el narcotráfico y crimen organizado, seguridad de puertos y aeropuertos, protección de objetivos estratégicos y hasta la seguridad en el campo (RESDAL, 2016). Recientemente, ante la crisis política que vive Nicaragua desde abril del 2018, Ortega utilizó su ejército para reprimir las manifestaciones, hecho que muchos han calificado como un mecanismo intimidatorio contra su propio pueblo (La Vanguardia, 21 de abril, 2018). 
Tabla 7. Tareas de seguridad ciudadana asumidas/apoyadas por las fuerzas militares en Centroamérica en el año 2016

\begin{tabular}{|c|c|}
\hline País & Descripción de la acción \\
\hline Guatemala & $\begin{array}{l}\text { Se da especial apoyo a la Dirección General del Sistema Penitenciario y a la } \\
\text { Policía Nacional Civil. Con respecto a la PNC el apoyo consta de: • Escua- } \\
\text { drones de Seguridad Ciudadana: Conformados por la reserva militar, los } \\
\text { Escuadrones de Seguridad Ciudadana se despliegan en } 9 \text { departamentos del } \\
\text { país, donde se enfocan en municipios priorizados por el Ministerio de Go- } \\
\text { bernación. Su rol es apoyar y reforzar el trabajo de la PNC. • Dos brigadas } \\
\text { militares fueron creadas con el objetivo declarado de proteger la vida y la } \\
\text { propiedad y neutralizar el crimen organizado, maras y delincuencia común: } \\
\text { la Brigada Especial de Operaciones de Selva en el municipio de La Libertad } \\
\text { (Petén) y la Segunda Brigada de Policía Militar en el municipio de San Juan } \\
\text { Sacatepéquez (departamento de Guatemala). }\end{array}$ \\
\hline \multirow[t]{3}{*}{ EI Salvador } & $\begin{array}{l}\text { En apoyo al Ministerio de Justicia y Seguridad Pública se ha estructurado } \\
\text { el Plan de Campaña Nuevo Amanecer con el propósito de contribuir a la se- } \\
\text { guridad de la población, mediante la ejecución de operaciones preventivas } \\
\text { antidelincuenciales, en forma coordinada con diferentes instituciones como } \\
\text { la Policía Nacional Civil, Dirección General de Migración y Extranjería y } \\
\text { Dirección General de Centros Penales. En el caso específico de la Policía } \\
\text { Nacional Civil: • Mediante el Plan de Operaciones Zeus se han desplegado } \\
\text { 3.100 efectivos de la Fuerza Armada en } 8 \text { fuerzas de tarea, localizados en } 9 \\
\text { departamentos y } 42 \text { zonas con mayor índice delincuencial que se encargan } \\
\text { de apoyar a la Policía Nacional Civil. }\end{array}$ \\
\hline & $\begin{array}{l}\text { - Comando Águila: En el marco del Plan de Prevención y apoyo a la Comu- } \\
\text { nidad se encuentran desplegados } 1.200 \text { efectivos militares en } 300 \text { Grupos } \\
\text { Conjuntos de Apoyo a la Comunidad. }\end{array}$ \\
\hline & $\begin{array}{l}\text { - Comando Trueno: Conformado con tres unidades de Fuerzas Especiales } \\
\text { de Reacción (FER), efectuando operaciones conjuntas anti delincuenciales } \\
\text { de intervención rápida en todo el territorio nacional, con el concepto de } \\
\text { apoyo a actividades de seguridad pública. }\end{array}$ \\
\hline
\end{tabular}




\section{País}

\section{Descripción de la acción}

Las fuerzas militares en Honduras cuentan con dos programas específicos que apoyan las tareas de seguridad ciudadana:

- Policía Militar de Orden Público: Es un Comando Especial de las Fuerzas Armadas. Sus efectivos se someten a las mismas pruebas de confianza que se le practican a la Policía Nacional. Funciona acompañada de jueces y fiscales con jurisdicción y competencia nacional. Entre sus funciones están:

a. Actuar rápidamente en circunstancias de inseguridad que afecten el orden público y constituyan situaciones de emergencia o que afecten a las personas o los bienes.

b. Cooperar en la recuperación de zonas donde haya presencia de crimen organizado.

c. Ejercer tareas de investigación e inteligencia.

d. Efectuar capturas y poner a disposición de las autoridades a quienes detengan. - Unidad Policial TIGRES: Opera dentro de la Estrategia Inte-

Honduras rinstitucional en Seguridad y Toma Integral Gubernamental de Respuesta Especial de Seguridad. El objetivo es proveer una respuesta a las principales amenazas a la seguridad pública, a través de la promoción de la coordinación entre instituciones estatales tales como la Policía Nacional, el Ministerio Público, etc.

Es una unidad especial de la Policía Nacional con la conducción del Director General, que puede requerir el apoyo de las fuerzas militares.

Funciones:

a. Combatir las manifestaciones de inseguridad a través de actividades policiales e interdisciplinarias.

b. Protección de la vida y de la propiedad.

c. Mantenimiento del orden público, prevención del delito, controles y arrestos.

d. Todos sus miembros deben someterse a pruebas de confianza.

El Ejército de Nicaragua desarrolla diferentes planes en el ámbito de apoyo

Nicaragua a la comunidad: Lucha contra el narcotráfico y crimen organizado, seguridad de puertos y aeropuertos, protección de objetivos estratégicos y seguridad en el campo.

Nota: Elaboración propia a partir de la información obtenida de RESDAL (2016) Capítulo 17: El Salvador, Capítulo 18: Guatemala, Capítulo 19: Honduras y Capítulo 21: Nicaragua.

En esta misma línea, en el 2016, los países de Guatemala, Honduras y Nicaragua lanzaron una fuerza regional contra las pandillas y el crimen organizado conformada de manera conjunta entre policía y ejército de los tres países. A 
pesar de que los mismos países admiten que las pandillas producen violencia delincuencial, esta materia es de seguridad ciudadana y no de defensa.

La decisión de unirse para combatir a estas organizaciones criminales se tomó luego que Guatemala y Honduras denunciaron la presencia de los delincuentes que desde El Salvador atraviesan las fronteras de sus países, lo que estaría ocurriendo desde que el gobierno salvadoreño puso en marcha nuevos planes para combatir a las pandillas, creando fuerzas elites que los persiguen, lo que los habría obligado a salir rumbo a Honduras y Guatemala. El gobierno hondureño ha reconocido que las pandillas son responsables en gran parte de la violencia delincuencial en ese país (El Universo, 3 de noviembre de 2016).

Aunque se han creado y fortalecido estas unidades especiales de trabajo en conjunto entre PNC y FFAA para la lucha contra el narcotráfico, hay pocos registros de enfrentamientos entre militares e integrantes de pandillas o de bandas criminales transnacionales que realmente verifiquen la efectividad de estas fuerzas "en conjunto" a nivel regional (Villalobos, 2016). Además, de no generar grandes resultados en materia de seguridad ciudadana, el trabajo en conjunto de las fuerzas militares y las Policías Nacionales Civiles no es conveniente debido a que poseen naturaleza, doctrina y funciones diferentes. En efecto, como lo señaló la Corte Interamericana de Derechos Humanos, y lo reafirman los diferentes enfoques teóricos analizados al inicio de este artículo, las fuerzas militares están formadas para ir contra un objetivo común y exterminarlo, no para la protección de civiles ni para la seguridad pública (CEJIL, 2011).

Con respecto a la participación política de los cuerpos militares, se ha identificado una serie de casos a nivel regional. En El Salvador, el expresidente Funes en el año 2011 nombró a David Munguía, un militar y exministro de Defensa como Ministro de Seguridad, después de 19 años de ser dirigido solo por personal civil (El Faro, 23 de noviembre del 2011). Este nombramiento quebrantó los compromisos asumidos en los Acuerdos de Paz, así fue calificado por la Sala de lo Constitucional de este país en el voto de inconstitucionalidad número 4-2012 del 2013, que logró la destitución de este nombramiento. Asimismo, este voto de inconstitucional fue trascendental no solo para reafirmar que militares o exmilitares no pueden ascender a puestos políticos, sino que subraya la naturaleza de las fuerzas militares y su función en la seguridad nacional y su peligrosa actuación en la seguridad ciudadana. Se lee:

La acción militar generalmente reviste un carácter represivo. Ahora bien, ello no significa que se tilde a una institución como agente vulnerador de derechos fundamentales por su formación castrense; sin embargo, debe entenderse que su doctrina, régimen y adiestramiento no se encuentran 
encaminados a la prevención, sino, como ya se dijo, a la represión de las amenazas a la soberanía estatal. Es decir, el contexto competencial para la seguridad pública está ya prefigurado para otro tipo de ente, con una preparación distinta en todos sus niveles: la PNC.

D. Se concluye entonces que la dirección militar en instituciones de naturaleza civil y la intervención de fuerzas armadas en las calles para llevar a cabo tareas de seguridad pública invierte el principio de uso racional de la fuerza en el Estado Constitucional y Democrático de Derecho, pues coloca a sujetos entrenados militarmente y dedicados al uso máximo de la fuerza, en el papel de recurso regular u ordinario para la protección de la ciudadanía, multiplicando los riesgos del exceso.

Por otro lado, el presidente nicaragüense, Daniel Ortega, en el 2014 impulsó una reforma constitucional que permite el nombramiento de militares y policías en puestos de gobiernos, cuando el mandatario lo considere necesario por "razones de seguridad nacional" (El Nuevo Diario, 19 de febrero, 2014). También, por medio de una reforma al Código Militar, se autorizó la reelección del jefe del ejército. Estas reformas van en contra del principio promulgado en los Acuerdos de Paz sobre la subordinación del poder militar al poder civil. Sin embargo, Ortega, para justificar su posición, afirmó que el "ejército es un pueblo en armas" (El Nuevo Diario, 19 de febrero, 2014).

Para Ortega (que en el 2016 logro su segunda reelección consecutiva como presidente sumando un total de 14 años en el poder), el ejército se convirtió en uno de sus principales aliados para asegurar el ejercicio del poder como presidente. De hecho, durante la consulta que realizó el Congreso Nicaragüense a diversos sectores para construir su criterio técnico para aprobar la reforma de la Constitución Política de Nicaragua que derogaba la prohibición de la reelección indefinida del presidente (violando uno los principios básicos de las democracias, la alternancia en el poder), el jefe de la inteligencia militar del ejército de Nicaragua, el general Leonel Gutiérrez, expresó ante la Asamblea el respaldo total y absoluto del ejército a esta reforma constitucional (La Prensa, 8 de Noviembre de 2013). La reforma fue aprobada por el Congreso a inicios del 2014.

\section{Conclusiones/Discusión}

A partir del acercamiento teórico sobre el papel del ejército, se puede señalar que las fuerzas militares no deben ser consideradas como una organización parte de la sociedad civil; al contrario, ambas tienen características y naturalezas antagónicas muy difíciles de compatibilizar (según el enfoque organizacional-psicosocial). Además, las fuerzas militares poseen intereses propios y van a realizar alianzas solamente en aquellos contextos donde sea necesario para cumplir con 
sus intereses ${ }^{11}$ (enfoque corporatista) y la presencia de los ejércitos en procesos de transición del autoritarismo a la democracia son un factor limitante para lograr la consolidación de las democracias plenas (teoría de la modernización).

A pesar de que existen varios enfoques teóricos que señalan la amenaza de los ejércitos en Estados de derecho en consolidación, la evidencia presentada demuestra que las democracias incipientes de Centroamérica, a partir del siglo XXI, han iniciado un proceso de remilitarización y fortalecimiento militar. Esto, en detrimento de los Acuerdos de Paz y los avances de fortalecimiento de las policías nacionales civiles en la década de los noventas. Las fuerzas militares, que se creyeron haber debilitado después de los Acuerdos de Paz, han vuelto a ser un actor protagónico de la esfera política y de seguridad de los países de la región. Lo más grave de la situación no es solo el fortalecimiento de estos cuerpos armados y la creación de policías militares, sino que este proceso se ha realizado en detrimento de las fuerzas policiales civiles las cuales tenían que verse fortalecidas a lo largo de los años, según los Acuerdos de Paz y el TMSD de la década de los años noventa.

Cabe resaltar que, aunque los Acuerdos de Paz expresamente promovían el "balance de fuerzas" (Esquipulas I), la "detención de la carrera armamentista y el asegurar un equilibrio cívico-militar" (Acuerdo de Contadora), los países fueron incapaces de concretar y operativizar mecanismos para asegurar su cumplimiento, y fue muy difuso para la región pasar del papel a la acción. Rivera ${ }^{12}$ (15 de junio del 2017) señala que "a pesar de que el Acuerdo de Contadora proponía el diseño y la elaboración de un instrumento que especificará no sólo el inventario del equipo militar que tenía cada país, sino que también proponía incluir metas anuales para la diminución porcentual tanto del presupuesto, efectivos y equipo militar en cada país. No obstante, este instrumento no se logró concretar en las negociaciones entre los países y prácticamente se tuvo que sacar de las mismas". La remilitarización de la región ha avanzado ante la reversión

11 Supuesto que se hace evidente en Nicaragua ante la crisis política del 2018, donde el Ejército ha quitado su respaldo al Gobierno de Ortega. Sánchez (El Mundocr, 26 de junio, 2018) señala que el Ejército ha emitido dos comunicados para comprometerse a no reprimir a los manifestantes, hacer un llamado al diálogo y al cese de la violencia, a pesar de que el mandato del gobierno de Ortega sea otro. Personas expertas, como Orozco y Cuadra (citados por El Mundocr), afirman que el comportamiento del Ejército, que constitucionalmente debe ser una institución "apartidista", "apolítica" y "no deliberante", tiene relación principalmente con la defensa de intereses económicos. A través el Instituto de Previsión Social Militar, su "brazo empresarial", dispone de constructoras, residenciales, inmobiliarias, hospital, financieras, acciones en la Bolsa de Valores de Nueva York y otras inversiones (El Mundocr, 26 de junio, 2018). Por lo anterior, deben cuidar su imagen y no promover una ingobernabilidad total que pueden afectar sus intereses económicos.

12 Carlos Rivera, exvicecanciller de Costa Rica 1986-1990 y uno de los principales figuras mediadoras y negociadoras de los Acuerdos de Paz y su implementación. 
del frágil equilibrio cívico-militar anhelado por los grupos gestores de la paz centroamericana.

La violencia política del siglo XX ha mutado a una violencia social y criminal provocada por las nuevas condiciones socioeconómicas de estos países en el siglo XXI. La insostenible situación de violencia en los países del norte de Centroamérica, agregada a factores como la inexperiencia de estos gobiernos democráticos en resolver los problemas públicos, Estados de derecho en construcción, débiles policías civiles nacionales y la ausencia de políticas preventivas en el pasado han presionado a los quienes toman decisión de estos países a buscar soluciones cortoplacistas debido al descontento de sus pueblos; soluciones que han sido dirigidas al fortalecimiento militar y el involucramiento de las fuerzas militares en asuntos de seguridad ciudadana.

Es de suma importancia recalcar que el discurso de fortalecimiento de las fuerzas militares de Guatemala, Honduras, El Salvador y Nicaragua es otro al ya descrito en las décadas de 1960-80. Esta vez el fortalecimiento de los grupos militares se ha acompañado de un discurso de sustituir o reforzar el trabajo de las nunca logradas policías civiles profesionales. Sin embargo, la respuesta de los gobiernos centroamericanos es la misma: el fortalecimiento militar para luchar contra estos nuevos flagelos. Si bien es cierto que el crimen organizado es un problema transnacional, sus repercusiones a nivel interno son de delincuencia y violencia social, protagonizada por los mismos pueblos.

Los ejércitos en Centroamérica se han sobredimensionado y fortalecido para enfrentar a "enemigos" que no tienen tanques militares, soldados ni armamento bélico. El crimen organizado se debe enfrentar desde estrategias de inteligencia policial no con tanques de guerra (FUNPADEM, 2017). Ante tal situación, surge la duda de: ¿para qué los gobiernos centroamericanos siguen fortaleciendo a sus ejércitos?, a pesar de que el compromiso era detener su crecimiento y fortalecimiento según el Acuerdo de Contadora. Personas expertas señalan que cuando un país tiene ejército y en ausencia de guerra, este debe de buscarle "nuevas tareas" y darle "nuevo armamento bélico" con el fin de entretenerlo y evitar que repliegue su poder contra sus propios gobiernos, como sucedió en Centroamérica en el Siglo XX. Agregado a esto, como se identificó en la investigación, varios gobiernos centroamericanos han utilizado las fuerzas militares y las unidades especiales militares de las policías para reprimir e intimidar a sus propios pueblos. Específicamente en Nicaragua y Honduras se han visualizado como mecanismos de coerción ante movimientos civiles de oposición.

Costa Rica y Panamá tomaron un camino diferente a los demás países de la región y eliminaron sus ejércitos. Panamá, a pesar de que no tuvo guerras civiles 
en las décadas 1960-80, sí vivió bajo regímenes autoritarios de tutela militar (Arias, 2016, p.105). En 1948, Costa Rica suprimió las fuerzas militares y Panamá en 1989. Hoy ambas naciones disfruten conjuntamente de los mejores índices socioeconómicos, democráticos y de seguridad en la región. Los países de la región que no tienen fuerzas militares han logrado construir Estados de derecho y democracias plenas, y naciones pacíficas con crecientes índices socioeconómicas: "La ausencia de un estamento militar es vista como una de las razones para la notoria estabilidad institucional civil de Costa Rica en las últimas décadas. Y Panamá, sin Guardia Nacional, es hoy una nación pacífica y con el mayor crecimiento económico en América Latina" (BBC, 2 de junio, 2015).

En conclusión, es un espejismo aspirar a un equilibrio cívico "militar democrático en sociedades con un fuerte legado autoritario, democracias frágiles, Estados de derecho en construcción y baja cultura cívica como son Guatemala, Honduras, Nicaragua y El Salvador. Como lo señala Rosada (1999, p. 20), “el problema se da cuando las nuevas democracias que emergen de un pasado autoritario, se muestran incapaces de colocar y reorientar las estructuras y prácticas que heredan de los militares”.

Los países centroamericanos deben ser conscientes que actualmente la acumulación de variables en la región, como la presencia de democracias débiles, Estados de derecho aún en construcción, niveles altos de violencia, gobiernos con baja calificación en transparencia, figuras presidenciales con largos períodos en el poder, fuerzas militares realizando tareas de seguridad interna, y policías civiles muy débiles son factores similares presentes en la década de 1960 que provocaron las guerras internas en estos países (FUNPADEM, 2017). La presencia de estos factores debería constituir una alerta roja no solo para Guatemala, Honduras, El Salvador y Nicaragua, sino para los demás países de la región y organismos internacionales. La historia de Centroamérica no solamente se debe recordar, sino también ser un ejemplo de cómo prevenir que esta se repita en la región.

La mejor forma de prevenir que la historia se repita es lograr cumplir con los compromisos adquiridos en los Acuerdos de Paz desde hace tres décadas, principalmente el compromiso regional de reducción y limitación de los ejércitos militares de estos países.

Poner un alto a la remilitarización y a la securitización debe ser una prioridad de los gobiernos centroamericanos. Se deben limitar las actuaciones del ejército y de las policías militares paulatinamente hasta suprimirlos, y de manera paralela iniciar un mayor fortalecimiento de las policías nacionales civiles, con el 
fin de que estas cumplan la función por la que fueron creadas, según el espíritu de los Acuerdos de Paz.

Pues, ¿cuál es el futuro de la democracia en sociedades violentas, sin policías civiles profesionales y con ejércitos sobredimensionados históricamente acostumbrados al protagonismo político? Sin duda, ningún otro camino que repetir la historia centroamericana de los años 1960-80.

\section{Referencias}

Acuerdo de Esquipulas II. (1987). Recuperado de http://www.guatemalaun.org/bin/ documents/Esquipulas\%20II.pdf

ACNUR. (1986). Acta de Contadora para la Paz y la Cooperación en Centroamérica. Recuperado de http://www.acnur.org/fileadmin/scripts/doc. php?file=fileadmin/Documentos/BDL/2002/1566

Arias, R (2016). ¿Centroamérica consolidación democrática o democracias violentas?. Revista Decisiones, 1 (2).

Bulcourf, P., Reina, A. (s. f). Comprendiendo al Estado: Los aportes de Guillermo O’Donell a su reconceptualización en América Latina. Recuperado de http:// www.palermo.edu/cienciassociales/PDFCienciaPoliticaN2/n2_comprendiendopolitica5.pdf

Cárdenas, J. (2015). Esta es la experiencia de 4 países que militarizaron la seguridad ciudadana. La República. Recuperado de http://larepublica.pe/ politica/707439-esta-es-la-experiencia-de-4-paises-que-militarizaron-laseguridad-ciudadana

Carreras, R. (1996). Costa Rica en el contexto de la seguridad internacional. Revista Paz y Seguridad en las Américas, 9. Chile: FLACSO.

CEJIL (2011). Fortalecimiento de la militarización en el "triángulo norte" centroamericano contradice pautas internacionales en derechos humanos. Recuperado de: https://cejil.org/comunicados/fortalecimiento-de-la-militarizacion-en-el-“triangulo-norte"-centroamericano-contradice-

Comas, J. (11 de junio 1986). El imposible desarme centroamericano. El País. Recuperado de http://elpais.com/diario/1986/06/11/internacional/518824821_850215.html

Cordero, M., Zeledón, F. (1994). Gasto militar en Centroamérica: Apuntes para entender su discusión nacional en los recientes procesos políticos. 1990-1993. San José, Costa Rica: Instituto de Investigaciones en Ciencias Económicas, UCR. 
Corte de lo Constitucional El Salvador. (2013). Voto Inconstitucional N 4-2012.

Cuadra, E. (junio, 2017). Exposición: Seguridad balance entre fuerzas armadas y fuerzas policiales. FUNPADEM: II Foro de la Jornada de Reflexión: A 30 años de los acuerdos de Paz. San José, Costa Rica.

Dammert, L. y Díaz, J. (2006). ¿Politización de la seguridad o securitización de la política? Boletín del programa seguridad y ciudadanía, N. ${ }^{\circ} 2,2006$, Flacso Chile.

Ellis, J; Moore, R (mayo. 1974). School for Soldiers: West Point and the Profession of Arms. Londres: London University Press.

El Heraldo. (s. f.). Inicia operaciones fuerza militar guatemalteca de combate al narcotráfico. Recuperado de http://www.elheraldo.hn/mundo/431159-213/ inicia-operaciones-fuerza-militar-guatemalteca-de-combate-al-narcotrafico

El Nuevo Diario. (19 de febrero 2014). Ortega alaba al Ejército luego de aprobarse reforma constitucional. Recuperado de https://www.elnuevodiario.com.ni/ nacionales/311773-ortega-alaba-ejercito-aprobarse-reforma-constituci/

El Universo. (3 de noviembre, 2016). Triángulo Norte de Centroamérica lanzará fuerza regional contra pandillas y crimen organizado. Recuperado de https://www.eluniverso.com/noticias/2016/11/03/nota/5889112/triangulonorte-centroamerica-lanza-fuerza-regional-contra

Estado de la Región. (2017). Estadísticas de Centroamérica: Tasa de efectivos de policía nacional no militar. Recuperado de https://www.estadisticascentroamerica2017.estadonacion.or.cr/estadisticas-erca2017. html\#pol\%C3\%ADticos

Figueroa, C. (1994). Dictadura militar y transición democrática en Centroamérica. Recuperado de http://www.uca.edu.sv/revistarealidad/ archivo/4e27408284692dictadura.pdf

Finner, S. (1962). The man on horseback. London.

Foucault, M. (1983). Vigilar y castigar. México: Siglo XXI.

FUNPADEM. (2011). Elementos para una agenda de profundización de la democracia en Centroamérica: Diálogo de los países miembros del Sistema de Integración Centroamericana y México (1 ${ }^{\text {era }}$ ed.).San José, Costa Rica: Autor.

FUNPADEM. (2017). Sistematización del grupo focal "Seguridad: Balance entre Fuerzas Armadas y Fuerzas Policiales" A 30 años de la firma de los Acuerdos de Paz. San José. Costa Rica: Autor.

Horovitz, I., Trimberger, E. (1976). State power and politics of civil-military relations. Comparative politics, 8 (2). 
Huntington, S. (1956). Civilian Control and the Constitution. The American Political Science Review, 50 (3), 676-699.

Huntington, S. (1968). Political order in changing societies: this theory of civilmilitary relations. New Haven: Yale University Press.

Jonhson, J. (1964) The military and society in Latin America. Estados Unidos: Stanford University Press.

La Nación. (23 de agosto del 2013). Creación de policía militar levanta temor en Honduras. Recuperado de https://www.nacion.com/el-mundo/politica/creacion-de-policia-militar-levanta-temor-en-honduras/ZELM5TYLN5FBZPOZG4I27R2GIM/story/

La Prensa. (16 de octubre, 2013). Tropas van tras grupos armados. Recuperado de https://www.laprensa.com.ni/2013/10/16/portada/166339-tropas-van-trasgrupos-armados

La Vanguardia. (21 de abril, 2018) Opositores piden cese a la represión en Nicaragua que deja 10 muertos. Recuperado de http://www.lavanguardia.com/internacional/20180421/442843058641/opositores-piden-cese-a-la-represionen-nicaragua-que-deja-10-muertos.html

Lehoucq, F. (2015). La larguísima resaca de las dictaduras en Centroamérica. El Faro. Recuperado de http://elfaro.net/es/201509/academico/17382/Lalargu $\% \mathrm{C} 3 \% \mathrm{ADsima}$-resaca-de-las-dictaduras-en-Centroam $\% \mathrm{C} 3 \% \mathrm{~A} 9 \mathrm{rica} . \mathrm{htm}$

Liewen, E. (1960). Arms and politics in Latin America. New York: Praeger.

Lucham, R. (1971). A comparative typology of civil-military relations. Government and opposition, 6: 5-35. doi:10.1111/j.1477-7053.1971.tb00810.x

Matul, S., Segura, L. D. (2010). Evolución institucional de la seguridad en el marco del sistema de la integración centroamericana: 1995-2009. Coordinadora Regional de Investigaciones Económicas y Sociales (CRIES). Buenos Aires, Argentina.

Meléndez, F. (2009). Gobernabilidad democrática y de la seguridad en la región. En Trejos, M. (Comp.), El Salvador: La integración regional: Instrumento de desarrollo nacional. Las crisis y la seguridad (1 ${ }^{\text {era }}$ ed.). San José: Asociación Instituto de Estudios Superiores para el Desarrollo Humano Sostenible.

Murillo, C. (2003). La contribución centroamericana a la resolución de conflictos. Revista Relaciones Internacionales, 66: 49-60.

Nun, J. (1969) Latin America: the hegemonic crisis and the military coup. Institute for International Studies. 
O’Donell, G. (1972). Modernización y golpes militares. Teoría y comparación y el caso argentino. Instituto Torcuato Di Tella. Centro de Investigaciones en Administración Pública.

O’Donnell, G. (1973). Modernization and bureaucratic authoritanism: studies in south American politics. Institute for International Studies. Berkeley, California.

Oficina de las Naciones Unidas contra la Droga y el Delito, ONUDD (2007). Crimen $y$ desarrollo en Centroamérica: Atrapados en una encrucijada. Eslovaquia.

Orozco, M. (Enero-junio, 2003). Centroamérica: Puntos de conflicto después de los años de tormenta. Revista Pensamiento Propio, CRIES.

Policía Nacional de Guatemala. (2014). Dirección General de la Policía Nacional Civil -PNC-: Misión de la PNC. Recuperado de https://www.pnc.gob.gt/ index.php?option $=$ com_k2\&view $=$ item\&layout $=\mathrm{item} \& \mathrm{id}=163 \&$ Itemid $=210$

Policía Nacional de El Salvador. (s. f.). Marco Institucional de la PNC. Recuperado de http://www.pnc.gob.sv/portal/page/portal/informativo/institucion

Policía Nacional de Honduras. (2018). Dirección General de la PNC. Recuperado de http://www.policianacional.gob.hn/inicio

Policía Nacional de Nicaragua, (s. f.). Acerca de la Institución. Recuperado de http://www.policia.gob.ni/?page_id=12

Pye, L. (1962). Armies in the process of political modernization. En The Role of the Military in Underdevelopment Countries. Nueva Jersey: Princeton University.

Redacción Criterio. (8 de enero, 2018), Represión militar se incrementa en Honduras. Recuperado de https://criterio.hn/2018/01/08/represion-militar-se-incrementa-honduras/

RESDAL. (2010). Atlas comparativo de defensa. Recuperado de http://www.resdal. org/atlas/atlas-completo2010-espanol.pdf

RESDAL. (2012). Atlas comparativo de defensa. Recuperado de http://www.resdal. org/ebook/AtlasRESDAL2012/print/atlas-completo.pdf

RESDAL, (2014), Atlas comparativo de defensa. Recuperado de http://www.resdal. org/atlas-2014.html

RESDAL. (2016). Atlas comparativo de defensa. Recuperado de http://www.resdal. org/atlas-2016.html

RESDAL. (2016). Capítulo 17: El Salvador. Atlas Comparativo de defensa de América Latina. Recuperado de http://www.resdal.org/assets/atlas_2016_ esp_17.pdf 
RESDAL. (2016). Capítulo 18: Guatemala. Atlas Comparativo de defensa de América Latina. Recuperado de http://www.resdal.org/assets/atlas_2016_ esp_18.pdf

RESDAL. (2016). Capítulo 19: Honduras. Atlas Comparativo de defensa de América Latina. Recuperado de http://www.resdal.org/assets/atlas_2016_esp_19.pdf

RESDAL. (2016). Capítulo 21: Nicaragua. Atlas Comparativo de defensa de América Latina. Recuperado de http://www.resdal.org/assets/atlas_2016_esp_21.pdf

Sánchez, M. (26 de junio, 2018). ¿Qué papel juegan los militares en la crisis de Nicaragua? El Mundocr. Recuperado de https://www.elmundo.cr/que-papeljuegan-los-militares-en-la-crisis-de-nicaragua/

SICA. (1995). Tratado Marco de Seguridad Democrática (TMSD). Autor.

Redacción. (2 de junio, 2015). ¿Ahorran Costa Rica y Panamá por no tener ejército? BBC Mundo. Recuperado de http://www.bbc.com/mundo/noticias/2015/06/150601_economia_gasto_militar_panama_costa_rica_lf

Rivera, C. (15 de junio, 2017). Entrevista a Carlos Rivera Bianchinni por Hazel Villalobos Fonseca. San José, Costa Rica.

Rivera, R. (2009). Centroamérica: Dilemas de la Seguridad y Defensa Regionales. En Mathieu, Hans y Rodríguez (Eds.), Anuario 2009 de la Seguridad Regional en América Latina. Fundación Friedrich Ebert Stiftung.

Rojas, F. (1996). Centroamérica: Una nueva agenda de Seguridad. Revista Paz y Seguridad en las Américas, 9. 1996. FLACSO Chile.

Rojas, F. (Diciembre, 2011). Seguridad y Crimen en Centroamérica. En: Cortés, Zovatto \& at (compiladores), Elementos para una agenda de profundización de la democracia en Centroamérica. Fundación para la Paz y la Democracia.

Rojas, F., Álvarez, A. (2012). Seguridad humana: Un estado del arte. En Seguridad Humana, nuevos enfoques (1 $1^{\text {era }}$ ed.). San José, Costa Rica: FLACSO.

Rosada, H. (1998). El lado oculto de las Negociaciones de Paz: Transición de la Guerra a la Paz en Guatemala. Fundación Friedrich Ebert/Proyecto Nacional. Guatemala, 1998.

Rosada, H. (1999). Soldados en el poder: Proyecto Militar en Guatemala, 19441990 (1 $1^{\text {er }}$ ed.). San José, Costa Rica: FUNPADEM.

SA. (2 diciembre, 2011). Fortalecimiento de la militarización en el "triángulo norte" centroamericano contradice pautas internacionales en derechos humanos. CEJIL. Recuperado de: https:/www.cejil.org/es/fortalecimiento-militarizacion-triangulo-norte-centroamericano-contradice-pautas-internacionales 
Sáenz, R. (Julio-agosto, 2012). ¿Valió la pena?: Guerras civiles y democracia en Centroamérica. A propósito de «Revoluciones sin cambios revolucionarios», de Edelberto Torres-Rivas. Revista Nueva Sociedad. Recuperado de http:// nuso.org/articulo/valio-la-pena-guerras-civiles-y-democracia-en-centroamerica-a-proposito-de-revoluciones-sin-cambios-revolucionarios-de-edelberto-torres-rivas/

Stepan, A. (1973). Authoritarian Brazil: Origins, Policies and Future. Yale University Press, London.

Stepan, A. (1988). Rethinking military politics: Brazil and the southern cone. Princeton University Press. New Jersey.

Stimson, H., Bundy, M. (1949). On active service in peace and war (1 $\left.{ }^{\mathrm{er}} \mathrm{ed}.\right)$. Nueva York: Lovenstein Press.

Stouffer, S. (1949). The American soldier. Princeton University Press. Princeton.

Torres, E. (1997). Centroamérica, revoluciones sin cambio revolucionario. Nueva Sociedad (150): 84-89.

Urcuyo, C. (2009). Seguridad: Un reto para la gobernabilidad democrática. En M. Trejos (Comp.), El Salvador: La integración regional: Instrumento de desarrollo nacional. Las crisis y la seguridad (1 ${ }^{\text {era }}$ ed.). San José: Asociación Instituto de Estudios Superiores para el Desarrollo Humano Sostenible.

Villalobos, H. (22 de junio, 2016). Remilitarización de Centroamérica: ¿Repetimos La Historia? Blog de FUNPADEM Pensando desde Centroamérica. Recuperado de https://pensandodesdecentroamerica.wordpress.com/2016/06/22/ remilitarizacion-de-centroamerica-repitimos-la-historia/

Zinecker. (Abril, 2012). Más muertos que en la guerra civil. El enigma de la violencia en Centroamérica. Friedrich-Ebert-Stiftung, en San Salvador. Recuperado de http://library.fes.de/pdf-files/bueros/fesamcentral/09184.pdf 


\section{Apéndice 1}

Participantes del grupo focal del 23 de junio del 2017 "Seguridad: Balance entre Fuerzas Armadas y Fuerzas Policiales" A 30 años de la firma de los Acuerdos de Paz

\begin{tabular}{ll}
\hline \multicolumn{1}{c}{ Nombre } & \multicolumn{1}{c}{ Institución que representa } \\
\hline 1. Elvira Cuadra & Experta Nicaragüense en Seguridad Regional \\
\hline 2. Gustavo Campos & $\begin{array}{l}\text { Coordinador Planeamiento Estratégico, } \\
\text { Cancillería Costa Rica }\end{array}$ \\
\hline 3. Cristian Castro Camacho & $\begin{array}{l}\text { Especialista en Seguridad, } \\
\text { Colegio Universitario de Cartago. Costa Rica }\end{array}$ \\
\hline 4. Carlos Rivera Bianchinni & $\begin{array}{l}\text { Exvicecanciller Costa Rica 1986-1990. Presidente de la } \\
\text { Fundación para la Paz y la Democracia (FUNPADEM) }\end{array}$ \\
\hline 5. Alexis Sánchez & Ministerio de Justicia y Paz de Costa Rica \\
\hline 6. Francisco Javier Mazo & Agregado Militar de Colombia \\
\hline 7. Javier Sancho & $\begin{array}{l}\text { Experto en relaciones bilaterales Costa Rica-Nicaragua. } \\
\text { Diplomático costarricense }\end{array}$ \\
\hline 8. Álvaro Ramos & Consultor costarricense experto en seguridad nacional \\
\hline 9. Lina Barrantes & Fundación Arias \\
\hline 10. Carlos Wilches & Representante Embajada de Colombia ante Costa Rica \\
\hline 11. Javier González & Agregado Policial. Embajada de Panamá ante Costa Rica \\
\hline 12. Carlos Zamora & Cátedra de Seguridad Universidad de Costa Rica \\
\hline 13.Carlos Alvarado & $\begin{array}{l}\text { Guardacostas, } \\
\text { Ministerio de Seguridad Pública de Costa Rica }\end{array}$ \\
\hline 14. Hugo Bonilla & Fundación para la Paz y la Democracia (FUNPADEM) \\
\hline 15. Roberto Méndez & $\begin{array}{l}\text { Seguridad Privada. Ministerio de Seguridad Pública de } \\
\text { Costa Rica }\end{array}$ \\
\hline
\end{tabular}

